


\section{La nueva politica migratoria de Paraguay: derechos humanos y seguridad como pilares para el tratamiento político de la inmigración*}

\section{Silvana Santi**}

\section{Resumen}

A tono con las tendencias regionales, Paraguay ha reconfigurado recientemente su política migratoria. Enese camino, este país hallevado adelante muchas medidas para tratar la inmigración internacional, pese a que históricamente se ha caracterizado por ser un país emisor de población. Este artículo explora las tensiones emergentes entre los derechos humanos y la seguridad en los cambios recientes de la política inmigratoria paraguaya. Esta temática casi no ha sido abordada por la literatura académica y sirve de base para posteriores estudios comparativos. Analizando fuentes normativas e institucionales, se revela el contundente protagonismo de la categoría seguridaden las acciones llevadas adelante por la Dirección General de Migraciones (DGM) entre 2014 y 2019, que superan, incluso, a las acciones emprendidas en pos de los derechos humanos de los migrantes, pese a que es desde esta última óptica que el Estado paraguayo justifica los cambios políticos realizados en torno al tratamiento contemporáneo de los movimientos poblacionales.

Palabras clave: Paraguay; políticas migratorias; seguridad, derechos humanos; OIM.

\section{Paraguay's new migration policy: human rights and security as pillars for the political treatment of immigration}

\section{Summary}

In tune with regional trends, Paraguay has recently reconfigured its migration policy. In this way, this country has implemented several measures to deal with international migration, despite the fact that it has historically been characterized by being a country of origin. This article explores the emerging tensions between human rights and security in recent changes in the Paraguayan immigration policy. This topic has barely been addressed in the academic literature and serves as a basis for further comparative studies. By analyzing regulatory and institutional sources, we reveal the strong role of the category of security in the actions carried out by the General Directorate of Migration (DGM by its Spanish acronym) between 2014 and 2019, which even surpass the actions undertaken in pursuit of migrants' human rights, although it is from this latter point of view that the Paraguayan State justifies the political changes made to the contemporary treatment of population movements.

Key words: Paraguay; migration policy; security; human rights; IOM.

\section{Nova política para as migrações no Paraguai: direitos humanos e segurança como colunas do tratamento político migratório}

\section{Resumo}

Alinhado com as tendências regionais, o Paraguai refez recentemente a sua política migratória. Foi assim que dita nação perfilhou muitas regras para lidar com a migração internacional, ainda que tradicionalmente tenha sido classificado como um Estado emissor de população. Esta pesquisa estuda as tensões surgidas entre os direitos humanos ea segurançanas atuais mudanças da política migratória paraguaia. Esse tópico escassavez foi mencionado pela literatura acadêmica e é uma base para estudos comparativos ulteriores. Analisando fontes normativas e institucionais, revela-se o dominante rol da categoria de segurança no acionar efetuado pela Direção-Geral de Migrações (DGM) entre2014 e 2019, ultrapassando inclusive as ações executadas na procura dos direitos humanos dos expatriados, embora fosse com esta última perspectiva que o Governo paraguaio justifica as modificações políticas adotadas relacionadas com o tratamento atual dos movimentos populacionais.

Palavras-chave: Paraguai; políticas migratórias; segurança; direitos humanos; OIM.

* Artículo de reflexión.

** Doctoranda en Ciencia Política de la Universidad de Belgrano, Argentina. Magíster en Relaciones Internacionales (Universidad Nacional de Córdoba, Argentina), Licenciada en Periodismo (Universidad de Belgrano, Argentina). Miembro del Grupo de Estudios "Migraciones, Familias y Políticas Públicas" (IIGG-UBA) y del GT "Migraciones SurSur" (CLACSO). Correo electrónico: silvanasanti@hotmail.com. ORCID: https://orcid.org/0000-0002-7388-4631

Cómo citar este artículo: Santi, S. (2020). La nueva politica migratoria de Paraguay: derechos humanos y seguridad como pilares para el tratamiento político de la inmigración. Estudios de Derecho, 77 (169), 213-242 


\section{La nueva política migratoria de Paraguay: derechos humanos y seguridad como pilares para el tratamiento político de la inmigración}

\section{Introducción}

Desde el inicio del nuevo siglo, varios ámbitos políticos sobre migraciones en la región sudamericana han establecido discursivamente una perspectiva de derechos humanos para encarar el fenómeno. Esta tendencia o "giro humanístico" puede advertirse en las políticas migratorias de diversos países y espacios de integración, como el Mercosur y la Unasur, y en el principal proceso consultivo regional sobre el tema, como es la Conferencia Sudamericana sobre Migraciones (CSM) (García, 2016, p. 109).

En este contexto, distintos Estados sudamericanos aprobaron o debatieron nuevas normativas migratorias que tienen en su centro una concepción de las migraciones desde una óptica de derechos humanos. Argentina fue pionera, sancionando en el año 2003 una nueva ley que reconoce a la migración como un derecho humano. Ecuador, en su Constitución de 2008, establece el derecho a migrar y el respeto a los derechos humanos de las personas migrantes como principio de sus relaciones internacionales. La ley de movilidad humana (2017) de ese mismo país andino, también hace referencia a los derechos humanos en varios de sus considerandos y artículos. La normativa migratoria de Uruguay (2008) reconoce el derecho a la migración como inalienable y deja asentado que la interpretación y aplicación de las disposiciones en su texto deben ser compatibles con los derechos humanos. En tanto, el respeto irrestricto de los derechos humanos está entre los principios de la ley de migración de Bolivia (2013). Recientemente, la normativa sobre migraciones de Brasil (2017) sostiene que uno de los principios y directrices que la rigen es la universalidad, indivisibilidad e interdependencia de los derechos humanos. Mientras tanto, el decreto legislativo de migraciones de Perú (2017), vela por el respeto de los derechos fundamentales de los extranjeros.

En este momento hay cuatro países de la región que están debatiendo reformas a su política migratoria: Chile, Paraguay, Colombia y Ecuador. Los tres primeros 
confluyen en la incorporación de la "migración ordenada"1 como directriz de sus planteamientos políticos sobre la materia. Mientras Chile, Paraguay y Ecuador han asentado ya en sus proyectos una perspectiva de derechos humanos.

Sin embargo, el apego a los derechos humanos no quiere decir que los países sudamericanos hayan descartado visiones de seguridad dentro de su agenda política sobre migraciones. Algunos estudios de los casos argentino (Courtis y Pacecca, 2007; Domenech, 2011a, 2013; Pereira, 2019), chileno (Concha Villanueva, 2018) y ecuatoriano (Ruiz Muriel y Álvarez Velasco, 2019) han resaltado que el reconocimiento discursivo de la migración como derecho humano convive con enfoques de seguridad y/o control migratorio. En este sentido, Domenech (2013) asegura que bajo el paradigma de la gobernabilidad migratoria:
(...) se desarrolla una política de control con rostro humano: amparado en el discurso de los derechos humanos para obtener la legitimidad necesaria para su instrumentación, el control sobre la inmigración irregular desplaza (no elimina) formas restrictivas o coercitivas, pero no con el propósito de hacer efectivos los derechos humanos de los in- migrantes, sino para obtener mayores resultados en la administración eficaz de los flujos migratorios. (Domenech, 2013p. 2)

Apuntando a acrecentar los antecedentes que indaguen en esta óptica, este artículo tiene por objetivo explorar las tensiones emergentes entre los derechos humanos y la seguridad en los cambios recientes de la política inmigratoria paraguaya. ¿Los derechos humanos han obtenido mayor atención que la seguridad o viceversa? ¿Cómo opera la inclusión de la idea de la "migración ordenada" en el binomio derechos humanos-seguridad? ¿Qué actores internacionales han colaborado en la puesta en marcha de la reciente "Política Nacional de Migraciones"?

A tono con las tendencias regionales, desde 2014, Paraguay ha reconfigurado su política migratoria, llevando adelante numerosas medidas para tratar la inmigración internacional en su territorio, pese a que históricamente se ha caracterizado por ser un país emisor de población. Con esta mira, se seleccionan y analizan distintos materiales oficiales que dan cuenta de los cambios de la política migratoria paraguaya, sobre todo a partir del 2003, año en el que se abre la nueva etapa de confección de una "Política Nacional de Migraciones". Entre los documentos recopilados, se presta atención principalmente a legislación sobre migraciones (leyes y decretos), comunicaciones institucionales de la Dirección General de Migraciones (DGM) e informes producidos sobre el tema por el Estado

1 Acerca del surgimiento e historización de esta concepción política (véase Santi, 2019).

Distintos trabajos, como los de Domenech (2011a; 2011b; 2013; 2017), Magliano y Clavijo (2011) y Zubrzycki (2018) han prestado atención a la "migración ordenada" vinculada al control y la gestión migratoria o gobernabilidad migratoria. 
paraguayo junto con organismos internacionales. El análisis documental de este estudio de caso revela un contundente protagonismo de la categoría seguridad en las acciones llevadas adelante por la DGM, principal institución estatal encargada de la inmigración. Estas superan, incluso, a las acciones emprendidas por la DGM en pos de los derechos humanos de los migrantes, pese a que es desde ésta última óptica que el Estado paraguayo justifica los cambios políticos realizados en torno al tratamiento actual de los movimientos poblacionales.

Si bien hay numerosos estudios académicos sobre el fenómeno emigratorio en Paraguay, existen menos antecedentes que hayan prestado atención a la política de inmigración internacional. Entre estos últimos, se pueden mencionar los textos de Souchaud (2008), Oddone (2011), Palau (2011) y Novick (2012), por ejemplo. En tanto, son escasos los trabajos focalizados en los recientes cambios producidos en este campo.

La estructura del artículo se divide en cinco secciones. La primera, de manera no exahustiva, caracteriza algunos puntos salientes del tratamiento políticonormativo de la inmigración en Paraguay. En un segundo apartado se da cuenta de los cambios recientes en la política migratoria de Paraguay desarrollados a partir del 2014. En tercer y cuarto lugar, se analizan las acciones desplegadas por la DGM, principal institución paraguaya encargada del tema, en torno a las categorías articuladoras sobre las que el Estado fundamenta discursivamente estos cambios: los derechos humanos y la seguridad. Finalmente, se elaboran unas conclusiones finales que ahondan en las consecuencias de la nueva política migratoria paraguaya, que ha allanado el camino hacia un proceso de securitización $n^{2}$ de las migraciones, en el cual la Organización Internacional para las Migraciones (OIM) ha tenido un papel central.

\section{Caracterización del tratamiento político-normativo de la inmigración en Paraguay}

Paraguay se ha caracterizado históricamente por ser un país expulsor de población. Datos oficiales recientes muestran que esta tendencia se sigue manteniendo: en 2015 la emigración contabilizaba 845.373 paraguayos/as, un $12 \%$ de la población; mientras la cifra de la inmigración alcanzaba 156.462 personas, representando un $2,4 \%$ de la misma (OIM, 2017). Sobre esta última cantidad, el porcentaje de inmigrantes provenientes de los demás países sudamericanos ascendía a 87,4 \% (OIM, 2017).

2 Siguiendo a Bigo (2002), la securitización de las migraciones se entiende como un enfoque que implica una serie políticas y prácticas ejecutadas por actores públicos y privados que promueven un vínculo entre las migraciones y la seguridad. 
Sin embargo, desde 1870, luego de la Guerra de la Triple Alianza, Paraguay ha mantenido políticas promotoras de la inmigración que, de modo paradójico, han impulsado la emigración (Oddone, 2011). Las Cartas Magnas paraguayas de 1870 y 1940 fomentaban la inmigración expresamente americana y europea. Tanto en la Constitución de 1870 como en la de 1967, la inmigración se establecía en relación con el aporte que podía hacer al desarrollo económico del país.

A modo ilustrativo, Oddone (2011) divide la inmigración hacia Paraguay en tres periodos: el primero ${ }^{3}$, desde 1870 hasta inicios del siglo XX se caracteriza por el impulso a la conformación de colonias agrícolas de inmigrantes europeos, aunque sin grandes frutos; el segundo periodo, se delinea desde la ley migratoria de $1903^{4}$, con el emplazamiento de nuevas colonias de inmigrantes que permanecen en el territorio y logran ser más estables que en la anterior etapa; el tercer periodo, se produce entre las décadas de los setenta y los ochenta con la llegada de una mayor cantidad de inmigrantes, destacándose el flujo brasilero ${ }^{5}$. La información estadística disponible señala que en 1880 los inmigrantes representaban un 3,2 \% de la población total del país; en tanto, en la primera década del siglo era solo un $0,7 \%$ y entre 1910 y 1920 aumenta a un 0,9\%, cayendo a un 0,4 \% en la década siguiente, aumentando a 1,3\% durante los años treinta, y reduciéndose nuevamente hasta 0,6 \% entre 1940 y 1960 (MRE, OIM y UNFPA, 2003). Sin embargo, varios autores advierten que hay que tomar con cautela estas cifras (MRE et al., 2003; Palau, 2011). Otras fuentes como son los censos de población, apuntan que, sobre el total de población, los nacidos en el extranjero representaban un 3,4 \% en 1971, un 5,6 \% en 1982, y un 5,5 \% en 1992 (MRE et al., 2003).

Tras el fin de la dictadura del general Alfredo Stroessner (1954-1989), con la llegada de la democracia se promulgó la nueva Constitución paraguaya en 1992, en la cual, además de los derechos, garantías, y libertades fundamentales incorporadas, se estableció que la temática migratoria debía reglamentarse por ley considerando los convenios internacionales (Novick, 2012) ${ }^{6}$.

Es así que en 1996 se aprobó la Ley de migraciones n. 9787 que aún hoy está en vigencia. López (2012) precisa que el foco de la misma está en la inmigración, a la que se le dedican 118 artículos frente a los 22 referidos puntualmente a la emigración. Esta norma le otorga al Estado un fuerte control social, protegiendo

3 En este lapso se promulgó la Ley de Inmigración y Colonización (en 1881).

4 Luego devino una nueva Ley de Inmigración en 1937, que favorecía la inmigración de ciertas profesiones.

5 Una mención especial merece el fenómeno de "brasiguayos”. Este tipo de inmigración brasilera con características de circularidad ha sido ampliamente estudiado (Marques, Rodrigues, De Almeida Rezende, Soares y Vélez, 2013).

6 Un antecedente de esta apertura incipiente fue la Ley n. ${ }^{\circ} 1 / 90$ sobre el Código electoral, la cual concedía a los extranjeros residentes la posibilidad de elegir y ser elegidos en el ámbito municipal. Por cuestiones de espacio, no se ahondará en la demás normativa electoral y su relación con la inmigración.

$7 \quad$ Fue reglamentada un año después a través del Decreto 18.295 de 1997. 
el empleo interno, defendiendo las fronteras, seleccionando a los migrantes y reconociéndoles limitados derechos, en definitiva, es “(...) cercana a la ideología de los gobiernos militares y su percepción geopolítica de las migraciones" (Novick, 2012, p. 88) ${ }^{8}$. El texto de la Ley n.. 978 (1996) promueve la inmigración calificada con fines de desarrollo, dando preferencia a quienes posean capital y a los agricultores destinados a proyectos de colonización en áreas determinadas por el Estado. Esta misma normativa también impide la admisión de extranjeros con enfermedades infectocontagiosas, transmisibles o mentales; así como aquellos que posean antecedentes penales, que ejerzan la prostitución o trafiquen drogas, quienes no posean profesión u oficio o practiquen la vagancia, mendicidad, ebriedad y quienes ya hayan sido expulsados. Además, la ley migratoria prohibe trabajar y dar trabajo o alojamiento a los extranjeros que residan "ilegalmente" en el país (art. 62; art. 63; art. 69, Ley n.․ 978, 1996). Atendiendo a esta rigidez, la normativa estipula que la "irregularidad" es causal de expulsión. Como observa Novick (2012), la categoría inmigrante en Paraguay ha sido construida “(...) como una amenaza que puede afectar la seguridad nacional" (p. 108).

En pocas líneas, la ley migratoria paraguaya tiene un fuerte sesgo económico, a través de la instrumentalización y justificación de la migración como factor promotor del "desarrollo" económico y securitario, por medio de la exaltación de la vigilancia sobre la irregularidad administrativa de los inmigrantes. La normativa sobre migraciones otorga un rol preponderante a la DGM, dependiente del Ministerio del Interior, como institución encargada de los asuntos migratorios. La DGM operativiza controles migratorios, entre ellos los de permanencia que la habilitan a hacer inspecciones en los lugares de trabajo y alojamiento, a aplicar sanciones, a regularizar a los "migrantes ilegales" y a disponer el rechazo y/o expulsación de extranjeros (Ley n.o 978 de 1996, art. 142).

Como otros países sudamericanos, el Estado paraguayo a inicios del nuevo milenio comenzó a dar pasos para redefinir su política migratoria. A pesar de continuar con una ley migratoria restrictiva y asentada en la seguridad interna, Paraguay firmó en el año 2000 la Convención internacional sobre la protección de los derechos de todos los trabajadores migratorios y de sus familiares ${ }^{9}$ y ratificó numerosos instrumentos jurídicos para la defensa de los derechos humanos entre 2001 y $2002^{10}$. Otro cambio importante se dio también en el año 2000 a partir de

8 De hecho, la Ley migratoria n. 978 es una "copia casi in extenso" del texto de la anterior Ley n.․ 470 de 1974, promulgada por Stroessner, que a su vez copia el Decreto del 28 de febrero de 1947 de Uruguay (OIM, 2013, p. 19). Esto da cuenta de que las normativas replican históricamente tendencias sobre los modos de pensar el fenómeno migratorio, como sucedió con la nueva ley migratoria argentina citada en la introducción.

9 Fue adoptada varios años después por medio de la Ley n. 3.452 de 2008.

10 Entre ellos: el estatuto de Roma de la Corte Penal Internacional; la convención internacional sobre la eliminación de todas las formas de discriminación racial; la convención para la prevención y sanción del delito de genocidio; el convenio internacional para la represión de los atentados terroristas cometidos con bombas; el segundo protocolo del 
una reunión bilateral sobre migraciones con Brasil, cuando el Estado paraguayo conformó un Grupo de Trabajo Interinstitucional (GTI) ${ }^{11}$ para forjar su posición frente a los movimientos poblacionales fronterizos. Este equipo actuó como un espacio germinal para los cambios suscitados en la política migratoria paraguaya que pueden rastrearse hasta hoy, sobre todo luego de la incorporación, por Decreto n. ${ }^{\mathrm{o}} 18.467$ de 2002, de la OIM y del Fondo de Población de las Naciones Unidas (UNFPA, por su sigla en inglés) ${ }^{12}$. Aquí ya se comienza a evidenciar que la migración se posiciona como un tema emergente para Paraguay y que va de la mano de la política exterior y la cooperación internacional. Leído en el contexto sudamericano, la aparición de la OIM en el escenario paraguayo es clave debido al rol e incidencia de este organismo en los cambios adoptados en materia de políticas migratorias a inicios de nuevo milenio en Argentina ${ }^{13}$, Ecuador ${ }^{14}$, Colombia $^{15}$, por mencionar solo algunos ejemplos. La OIM ha tenido un papel central en la difusión del paradigma de la gobernabilidad migratoria en la región (Domenech, 2013), marco de entendimiento que encaminará muchas de las acciones del Estado paraguayo en la senda del control migratorio, como veremos más adelante.

El Decreto n. 18.467 de 2002 posibilitó que el Estado paraguayo, acompañado y asesorado por la OIM y UNFPA, ejecutase el Proyecto: "Lineamientos para la elaboración de una Política Nacional de Migraciones” y elaborase propuestas para trazar la política actual sobre movimientos poblacionales. Esta "Política Nacional de Migraciones" enfatizaba cinco ejes estratégicos: (1) fijar a la población en su lugar de origen; (2) generar migraciones; (3) intervenir en los flujos migratorios para lograr su modificación; (4) recuperar a la población nacional radicada en el extranjero; y (5) incorporar al migrante ya establecido en la sociedad paraguaya (MRE et al., 2003). En el primer eje, el término "fijar" se refería a promover políticas para retener a la población paraguaya y evitar su desplazamiento interno y externo. En tanto, el segundo punto alentaba la migración selectiva tanto de extranjeros como de inmigrantes internos paraguayos, mientras el siguiente proponía políticas de regulación para restringir, canalizar o facilitar ciertos desplazamientos. El

pacto internacional de derechos civiles y políticos, destinado a abolir la pena de muerte; la convención internacional contra la toma de rehenes; el protocolo facultativo de la convención sobre los derechos del niño relativo a la venta de niños, la prostitución infantil y la utilización de niños en la pornografía; los artículos 21 y 22 de la convención contra la tortura y otros tratos o penas crueles, inhumanos o degradantes.

11 Estaba integrado por representantes del Ministerio de Relaciones Exteriores; Ministerio del Interior - Dirección General de Migraciones; Ministerio de Justicia y Trabajo; Ministerio de Agricultura y Ganadería; Ministerio de Educación y Cultura; Ministerio de Industria y Comercio; Secretaría del Ambiente; Secretaría Técnica de Planificación; y del Instituto de Bienestar Rural (Decreto n.․ 11.484 de 2000).

12 Por el mismo decreto, también se incluyeron el Ministerio de Defensa Nacional y la Secretaría de Desarrollo para Repatriados y Refugiados Connacionales.

14 Véase Santi (2017).

15 Véase Clavijo Padilla (2014). 
cuarto eje, promovía medidas para impulsar el retorno de paraguayos. En tanto, el último apuntaba a medidas para la inserción de inmigrantes regulares y la regularización de aquellos considerados "ilegales". Alineada con los preceptos de la gobernabilidad migratoria, la "Política Nacional de Migraciones" alentaba el control (in)migratorio, promoviendo la inmigración selectiva (regulando, restringiendo, canalizando o facilitando cierto tipo de inmigrantes) y la regularidad.

La "Política Nacional de Migraciones" señalaba como problemas a los "migrantes indocumentados", cuya cifra desconocida era percibida como "alta"; la doble nacionalidad de los paraguayos; la naturalización y nacionalización de extranjeros en Paraguay; la extensión de nacionalidad vía ius-sanguinis para paraguayos; la falta de una base de datos sobre visados; el "vacío legal" que había que subsanar para poder cancelar la radicación a los migrantes que no cumplían la ley; la falta de regulación para casos de trata y tráfico de migrantes, entre otros (MRE, 2003 et al., , pp. 41-42). Además, enfocaba a la migración como una amenaza explícita, afirmando que: "es evidente que los problemas referidos a la migración tienen directa vinculación con aquellos referidos a la defensa y seguridad internas" (MRE, 2003 et al, p. 50). En términos generales, los lineamientos de la política migratoria paraguaya dejaban entrever una asociación de la inmigración con la seguridad; una preocupación por los derechos humanos, sobre todo al momento de hablar de los paraguayos en el exterior; y una perspectiva utilitaria de la inmigración y la emigración como factores de contribución al desarrollo, ponderando a aquellos que provean capital de inversión y/o fuerza de trabajo. En varios pasajes del informe prevalecía una mirada negativa sobre los inmigrantes, llamando a que la renovación de la normativa migratoria prestase atención a "(...) [el] cumplimiento de las normas referidas a los delitos ambientales, en los cuales incurren reiterada y masivamente ciertas corrientes migratorias" (MRE, 2003. et al, p. 42); la preferencia de mano de obra extranjera en detrimento de la nacional, al expresar que "el empresario extranjero debe demostrar que no existe mano de obra nacional capacitada para tal tarea para justificar la contratación de extranjeros" (MRE et al., 2003, p. 44); y la preocupación por ciertos flujos asegurar que "hay (...) una resistencia cultural de los migrantes brasileños hacia la cultura nacional paraguaya" (MRE, 2003 et al., p. 54). Si bien este informe resaltaba cuestiones de derechos, lo cual representaba una novedad en materia migratoria, persistía en representar a la inmigración como una amenaza para la seguridad, el medio ambiente, el trabajo y la cultura del Paraguay, construyendo al extranjero como una alteridad destructiva sobre la que había que tener control.

No obstante, de acuerdo con OIM estos lineamientos no se replicaron en políticas oficiales y fueron casi inexistentes las acciones programáticas estatales para incidir en los procesos migratorios:

(...) tanto para promover y facilitar migraciones ordenadas, como para fomentar el arraigo, mejorar la condición jurídica, laboral y social de 
las personas migrantes; vigilar y bregar por el estricto cumplimiento de los convenios internacionales que garantizan el pleno ejercicio de los derechos del migrante (...), entre otros aspectos propios de una política migratoria. (OIM, 2014, p. 16)

Aunque, como veremos más adelante, varias de las sugerencias sobre política migratoria se plasmaron años después en medidas específicas que hilvanaban la migración, la seguridad, la regularidad migratoria y los derechos humanos.

La "Política Nacional de Migraciones" recomendaba atender la irregularidad migratoria y los acuerdos regionales en el marco del Mercosur y la CSM. Utilizando el principio de reciprocidad, Paraguay impulsó por Decreto n.o 9.032 de 2007 una regularización extraordinaria para ciudadanos argentinos en correspondencia con el Programa Nacional de Normalización Documentaria (conocido como "Patria Grande"), implementado por Argentina un año antes. Acerca de los acuerdos de integración regional, Paraguay ratificó en 2009 el Acuerdo sobre Residencia para Nacionales de los Estados Partes del Mercosur y también el Acuerdo sobre Regularización Migratoria Interna de Ciudadanos del Mercosur. Otro paso en este sentido, fue la sanción de Ley n. 4.429 de 2011 que regularizaba la residencia de extranjeros en situación migratoria irregular. Esta "ley de amnistía", como se denominó informalmente, fue un reclamo de los grupos de migrantes organizados, los cuales durante 2010 colaboraron en su elaboración junto con la DGM (OIM, 2011). Estas dos últimas acciones se llevaron a cabo durante la gestión presidencial de Fernando Lugo ${ }^{16}$, quien había considerado a la migración (sobre todo la emigración) dentro de sus discursos de campaña electoral.

Otro elemento que ayuda a interpretar la política migratoria contemporánea de Paraguay es el lazo que ese Estado ha entretejido con la OIM a través de los años. A mediados de 2008 comenzó a implementarse un "Programa integral para el fortalecimiento de las capacidades institucionales del gobierno de $\mathrm{Pa}$ raguay en materia migratoria y lucha contra la trata de personas", dirigido a funcionarios de la DGM y del Ministerio de Relaciones Exteriores (PNU, UNFPA, UNICEF, UNIFEM y OIM, 2009, p. 157). Estos cursos brindaron capacitación a un centenar de personas, con el rol de "formadores de formadores en la temática", provenientes de sectores de la sociedad civil organizada, entre ellos integrantes de la Mesa Interinstitucional para la Prevención y Combate a la Trata de Personas, de la Red Trinacional (de la Triple Frontera) y miembros de varias ONG de Argentina, Brasil y Paraguay (OIM, 2011, p. 67). Esto abrió paso a la confección de una política nacional para la prevención y combate a la trata de personas para el periodo 2010-2019.

Fue mandatario entre 2008 y 2012. Lugo representó una coalición integrada por movimientos políticos y sociales que rompió con 61 años ininterrumpidos de gobiernos del Partido Colorado en Paraguay (López, 2010). 
Este tipo de formación constituye una línea histórica de trabajo de la OIM como institución. Desde la década de los sesenta hasta hoy, este organismo se ha especializado en el asesoramiento a gobiernos (particularmente del hemisferio sur) y la capacitación de actores públicos y privados en políticas migratorias con un enfoque preponderante de control o gobernabilidad/gestión migratoria. El asesoramiento y la capacitación han sido los mecanismos reproductivos centrales utilizados por la OIM para promover la idea de la "migración ordenada", alentando políticas y prácticas de control migratorio. Como ejemplo de políticas, se pueden citar las de regularización, mientras que la incidencia de OIM en la tecnificación de los sistemas de control migratorio y sus procedimientos han tenido impacto sobre las prácticas. En este sentido, Paraguay no ha sido la excepción, según se verá en las próximas páginas.

Este paneo de antecedentes políticos-normativos sirve para iluminar y comprender los cambios acelerados de la política migratoria paraguaya, sobre todo a partir de 2014, como se detallará seguidamente.

\section{Hacia la "Política Nacional de Migraciones": ¿Disyuntiva entre derechos humanos y seguridad?}

La política sobre inmigración de Paraguay había pivotado entre un fuerte sesgo securitario y una incorporación escalonada de varios instrumentos jurídicos en favor de los derechos humanos de los migrantes. En el año 2014 se produjo el lanzamiento de una nueva etapa de formulación de la misma por medio de varios proyectos de cooperación interinstitucional entre la DGM y la OIM. Bajo el leivmotiv de "modernización migratoria", ambos actores trabajaron con el objetivo de construir una nueva política migratoria nacional que fuese la base para revisar la ley de migraciones de 1996. Según la OIM (2014), algunos de los ámbitos a atender eran: la reforma tecnológica, el mejoramiento de la gestión operativa y de la situación migratoria en Paraguay y la actualización de los sistemas de ingreso y egreso del país.

En 2015 con el apoyo técnico de OIM, representantes de la academia, organizaciones de la sociedad civil y migrantes, el Estado paraguayo aprobó formalmente la "Política Nacional de Migraciones". Por Decreto n.․․ 4.483 de 2015 se definieron las orientaciones de una política pública para las migraciones, que comprendían: elevar la calidad de la gestión migratoria, garantizar el respeto a los derechos humanos, y asegurar la gobernabilidad migratoria. A lo largo de este instrumento jurídico, la inclusión de la perspectiva de derechos humanos ${ }^{17}$ se presentaba

17 Hay una incorporación general del foco de derechos que permean los once principios generales de la "Política Nacional de Migraciones": principio de igualdad; principio de equidad social; principio de no discriminación; principio de equidad de género; principio de equidad intergeneracional; principio de protección integral e interés superior de 
como una de las principales justificaciones para este cambio político y además como un elemento de crítica a la ley migratoria de 1996 que no los invocaba. Ese documento reconoce como derechos fundamentales el derecho a no migrar y el derecho a migrar.

Las estrategias planteadas por el Estado paraguayo para llevar a cabo su nueva política migratoria se concentraban en: renovar la normativa migratoria en base a los principios de protección de los derechos humanos; reformar y adecuar la DGM; establecer una instancia de coordinación institucional sobre la temática; mejorar la información, datos e investigación vinculada a la migración; reconocer el derecho a la migración ordenada y a procesar solicitudes de refugio y asilo; prevenir y combatir delitos asociados al movimiento fronterizo, como la trata y tráfico de personas; dar mayor transparencia a la gestión pública de las migraciones; profesionalizar a los funcionarios migratorios; e implementar la política migratoria considerando la inserción de Paraguay en ámbitos especializados regionales e internacionales sobre migraciones (Presidente de la República de Paraguay, 2015, p. 17).

Las acciones a emprender por Paraguay sobre la inmigración dan cuenta del reconocimiento de los derechos humanos a los migrantes, al considerar que "la manifestación del interés en residir en el país es condición necesaria para adquirir el estatus de inmigrante y gestionar la residencia temporal o permanente" (Presidente de la República de Paraguay, 2015, p. 24). En esta dirección, también se reconoce discursivamente la facilitación de ingreso a personas desplazadas, el apoyo a la asociatividad migrante y al retorno. Sin embargo, otras de las acciones requeridas para alcanzar la "Política Nacional de Migraciones" viran hacia una óptica de seguridad, como el refuerzo de la vigilancia cuando se trate de asuntos de salud pública, el contacto con autoridades de otros países "con el fin de obtener información precisa sobre la intención de determinados grupos o familias que deseen radicarse en el territorio nacional, sea de manera temporal o permanente, o gestionar la reunificación familiar (...)" (Presidente de la República de Paraguay, 2015, p. 25), así como de los inmigrantes que lleguen a título individual.

Estos extractos muestran que Paraguay apela al discurso de derechos humanos al mismo tiempo que refuerza su lógica de control migratorio, extendiendo su alcance ya no solo a individuos sino a familias migrantes y utilizando la vía de la cooperación con otros Estados para cercar esa vigilancia. Esto podría encajar con las dinámicas de "control cooperativo" o externalización que Alvites Baiadera (2019, p. 136) menciona como parte del régimen de frontera sudamericano. Esa

los derechos de niños, niñas y adolescentes; principio de respeto a la diversidad cultural; principio de integración social; principio de respeto/reconocimiento a los derechos laborales; principio de reciprocidad; y principio de la congruencia (Anexo del Decreto n. 4.483 de 2015). 
autora refiere que para ello son necesarios acuerdos regionales o bilaterales. Sin embargo, atendiendo al texto del decreto paraguayo mencionado, las consultas entre autoridades migratorias o consulares que no conlleven la formalidad de un acuerdo explícito también pueden integrar ese "control cooperativo".

También se vislumbra la adopción por parte de Paraguay de la perspectiva de "migración ordenada", famosa por haber sido el eslogan de la OIM desde sus inicios y que ha sido popularizada actualmente a raíz del Pacto Global sobre Migraciones o Global Compact de 2018. Se expresa que:

La autoridad migratoria acogerá la inmigración ordenada y segura de familias y grupos humanos de acuerdo a los tratados y convenios internacionales suscritos por el Paraguay, priorizando la inmigración planificada conforme a convenios bilaterales. En este sentido, se estudiarán las mejores condiciones para canalizar los flujos de inmigración y su localización en áreas territoriales que permitan su asentamiento en condiciones dignas y su participación en la actividad económica y social de su elección, sin que ello impida el libre ejercicio de sus ocupaciones y profesiones habituales conforme con la legislación pertinente y las potencialidades del desarrollo económico y social, ambiental y ecológicamente sostenible del Paraguay. (Presidente de la República de Paraguay, 2015, p. 25)

El nexo entre migración, seguridad y derechos humanos que Pereira (2019) resalta del caso argentino, en Paraguay es posible compatible con la vinculación entre las mismas categorías y la idea de "migración ordenada" que se apoya en criterios de control y selectividad. En este ámbito, la selectividad en torno a la inmigración apela a criterios de seguridad y de utilidad para el Estado paraguayo. En tanto, los derechos humanos se subordinan a la "migración ordenada" delimitada por el Estado.

Otra muestra de ello es que la "migración ordenada" también se replicó en un título específico del proyecto de la nueva ley de migraciones, presentado ante la Cámara de Diputados paraguaya en 2016, que contó con asistencia técnica de la OIM. Allí se afirmaba que el Poder Ejecutivo regulará la "migración ordenada", priorizando para ello la firma de acuerdos bilaterales donde se fijen el número de inmigrantes y las actividades requeridas y una distribución territorial designada (Congreso Nacional de Paraguay 2016, art. 30, art. 31, art. 33). Este tipo de acuerdos no son nuevos en América Latina, numerosos fueron motorizados por la OIM y se llevaron a cabo bilateralmente para garantizar mano de obra migrante con dirección Sur-Norte, suscitando una verdadera "migración a la carta" que reproduce desigualdades ${ }^{18}$. La "migración ordenada" hace que la migración "ilegal" o "irregu-

18 Por ejemplo, se pueden mencionar los acuerdos de regulación y ordenación de flujos migratorios entre España con Colombia, Ecuador y República Dominicana. Algunos de estos se analizan en Santi y Clavijo (en prensa). 
lar" sea vista como un problema mundial que conlleva múltiples riesgos, haciendo de su "prevención" y “combate" una estrategia de intervención (Domenech 2017, p. 24). Al tener a la seguridad como meta, la "migración ordenada" propuesta por la OIM tiene como objetivo restringir la migración considerada inconveniente, entendiendo que para ello es necesario vigilar todo el trayecto migratorio de los flujos (Santi, 2019). Por ello, la firma de convenios migratorios es esencial para hacer efectivo el control perseguido y la selectividad deseada.

El Proyecto de Ley de migraciones de Paraguay, cuya discusión legislativa se encuentra postergada ${ }^{19}$, sigue las tendencias marcadas por la "Política Nacional de Migraciones": da atención a los derechos humanos, la "migración ordenada", pone un marcado énfasis en el control migratorio y posee articulado específico sobre trata y tráfico de personas. Estos temas integran la agenda política de la OIM y son una muestra de las sinergias compartidas con Paraguay.

Todos estos cambios en la política migratoria paraguaya han modificado la visión institucional contemporánea de la DGM, que se ha asentado sobre dos pilares interconectados: los derechos humanos acompañados por el control migratorio. Como se expresa oficialmente, la DGM ha pasado a "ser una institución comprometida con la integración de las personas y el respeto a los derechos humanos", pero además, a "estar a la vanguardia en el campo del Control Migratorio que contribuya a la seguridad de la población, mediante la adopción de tecnología moderna" (DGM, s.f.). Tomando estos nuevos pilares constitutivos, seguidamente se rastrean acciones y espacios de formación en los que la DGM ha participado ${ }^{20}$, para dar cuenta si efectivamente ha primado el interés de los derechos humanos por sobre la seguridad o viceversa.

\section{Acciones de la DGM referidas a los derechos de los inmigrantes}

La gobernabilidad migratoria impulsa a que los Estados muestren voluntad en dar cumplimiento a los compromisos internacionales de derechos humanos, como un paso esencial para lograr la legitimidad de sus políticas migratorias (Domenech, 2009). La necesidad de adaptar la normativa a las nuevas perspectivas internacionales en materia de política migratoria, así como alinearla a los compromisos de derechos humanos, fueron dos de los argumentos que se esgrimieron como motivación del proyecto de la nueva Ley de migraciones paraguaya. No obstante, en la agenda política de Paraguay el tema de los derechos humanos de los migran-

19 De acuerdo con la página web del Congreso paraguayo, véase Sistema de Información Legislativa (2019).

20 Se han considerado solo los ámbitos de cooperación oficial con otras instituciones del Estado, espacios multilaterales y países, sin considerar aquellos lazos establecidos con instituciones académicas u otras asociaciones civiles. 
tes ha estado presente en reuniones regionales como las de Mercosur y la CSM. También el asunto se ha tratado en espacios como los de la Red Iberoamericana de Autoridades Migratorias (RIAM), donde el país participa. Por ejemplo, en su reunión de 2015, a la que concurrrió la DGM, se habló de desarrollar competencias para los oficiales de migración acerca de marcos legales y protocolos para la protección de los derechos humanos de los migrantes, a la par de avanzar en capacitaciones, gestión de información migratoria, herramientas tecnológicas y biométricas, entre otras (DGM, 2015,14 de mayo). Este escenario replicaba la asociación derechos humanos-seguridad afín a la nueva política migratoria paraguaya. No hay que perder de vista que la legitimidad otorgada por el discurso de derechos humanos quita del foco de atención central, en el discurso público, de la seguridad y el endurecimiento del control migratorio. Es lo que Domenech (2013) ha acuñado como política de "control con rostro humano" (p. 2), que hace intermediar la legitimidad del discurso de los derechos humanos para instrumentalizar el control sobre la inmigración irregular.

Justamente, una política que enlazaba la irregularidad administrativa y el acceso a derechos de los migrantes fue abordada por la DGM y otras instituciones públicas en el marco del Plan Nacional de Derecho a la Identidad. Se plantearon como objetivo erradicar el subregistro de personas en localidades fronterizas paraguayas que, según estimaban, alcanzaba alrededor de un $10 \%$ de la población (DGM, 2016, 24 de junio). En 2016, la institución migratoria propuso promover el acceso a la documentación a extranjeros como paso previo al ejercicio de sus derechos, lo cual supone una declaración de prioridades por parte del Estado paraguayo. Esto no solo representaba una continuación de los programas de regularización que se llevaban adelante a partir de los acuerdos del Mercosur y de la perspectiva adquirida con la llamada Ley de amnistía de $2011^{21}$, sino que también se planteaba como un asunto de control sobre la población extranjera. Este enfoque expresa la tensión entre el binomio seguridad y derechos humanos en el contexto paraguayo. Los inmigrantes luego de ser sujetos del control de identificación podían ser considerados sujetos de derechos, planteándose así los derechos como una alternativa condicionada. Si bien, el Estado posee la monopolización de los medios legítimos de movimiento que hace depender a las personas de su autorización para desplazarse legítimamente (Torpey, 2006), se puede añadir que la permanencia de los inmigrantes también se ata a la autorización del Estado para que sea considerada legítima y los habilite como poseedores de derechos.

Los derechos humanos también fueron un tema de adiestramiento al interior de la DGM. En 2014, la OIM llevó adelante un ciclo de capacitación donde ese tema fue uno de los ejes (DGM, 2014, 1 de abril). El nexo derechos humanos y seguridad

21 En los años sucesivos, la DGM desplegó campañas y jornadas informativas sobre acceso a documentación y derechos, dirigidas a migrantes en distintos territorios de Paraguay. 
también estuvo dentro de la agenda. Gracias al apoyo de la Embajada de Estados Unidos en Paraguay, el encargado de seguridad de la DGM participó ese mismo año del curso internacional de derechos humanos, dictado por la Academia Internacional para el Cumplimiento de la Ley (ILEA, por su sigla en inglés), con sede en El Salvador. Los contenidos fueron relativos a derechos humanos en el ámbito de la seguridad (DGM, 2014,16 de julio). Este enfoque no es sorprendente, siendo que la ILEA, institución creada por iniciativa estadounidense, se dedica a dar instrucción sobre el combate del crimen transnacional.

Otra capacitación sobre derechos humanos de la que formaron parte funcionarios de la DGM fue el taller "Iniciativas regionales para la identificación y atención de niños, niñas y adolescentes migrantes”, que buscaba la promoción de recomendaciones de protección de derechos humanos. Este evento fue organizado en 20016 por la OIM y por el Instituto de Políticas Públicas en Derechos Humanos del Mercosur (IPPDH), con el apoyo de Brasil (DGM, 2016, 14 de julio).

Estos punteos dan cuenta de que Paraguay ha hecho algunos pasos formales recientes en cuestión de derechos de la población inmigrante. Aunque, pasar de una doctrina de seguridad nacional a una visión de derechos humanos conlleva a reparar en el camino las nuevas prácticas, que implican formas más sofisticadas de compatibilizar las viejas y las nuevas visiones. Como se precisa a continuación, este discurso estatal sobre los derechos humanos migrantes no puede soslayar el gran vuelco que Paraguay ha hecho en términos de securitización en tiempos de la nueva "Política Nacional de Migraciones". La renovación de su política migratoria le ha permitido a Paraguay ser percibido con mayor interés por parte de otros países y organismos internacionales, presentándose como un mercado potencial para la implantación de enfoques políticos y nuevos saberes técnicos para encarar el fenómeno migratorio.

\section{Acciones de la DGM referidas al nexo seguridad y migración}

Tanto la vieja política migratoria paraguaya como la nueva, proyectan fuertemente a la migración como un asunto de seguridad. Si bien se pretende dejar atrás la histórica perspectiva de doctrina de seguridad nacional que ha seguido Paraguay desde los años setenta, a inicios de esta década el país ha presentado una versión modernizada de seguridad que afina en cuestiones de vigilancia y control migratorio a la vanguardia de las tendencias globales. Como se reconoce en el borrador del Proyecto de Ley de migraciones de 2016, los cambios en las dinámicas migratorias en las últimas dos décadas llevaron al aumento de la migración interna, la emigración y del retorno de los paraguayos, y a un decrecimiento de la inmigración. Es decir, la emigración sigue siendo el principal fenómeno en Paraguay, lo que contradice el énfasis puesto en el desarrollo de políticas y prácticas vinculadas a la inmigración como tópico de seguridad. 
Esto sirve de puntapié para relevar que en Paraguay se ha propagado lo que Bigo (2006) llama una idea de (in)seguridad global ${ }^{22}$, que se alimenta de amenazas potenciales y es apuntalada por un campo de profesionales que "gestionan" ese "malestar" y que están en el centro de las transformaciones relativas a la vigilancia global. Esto ha provocado, de manera paradójica, que el mantenimiento del control soberano de las fronteras requiera de la cooperación con otros Estados y organismos internacionales a los que es inevitable ceder una parte de la soberanía (Torpey, 2018). Gracias a su "modernización migratoria", Paraguay se ha convertido en un campo de acción y atracción para los "servicios" de seguridad brindados por diversos actores internacionales. Esto ha conllevado a la incipiente constitución y desenvolvimiento de una cooperación securitaria sobre migraciones, que implica el establecimiento de lazos de colaboración con países y organismos internacionales con fines de control migratorio y fronterizo para la formación (capacitación en contenidos políticos y tecnológicos), provisión de servicios, y adquisición de sistemas tecnológicos y equipamientos; lo que impacta directamente en las prácticas a través del cambio de concepciones y procedimientos. Existe un pronunciado interés de cooperación securitaria sobre migraciones entre Paraguay y varios países y organismos internacionales en lo que se refiere a asuntos de seguridad, control migratorio y vigilancia fronteriza, que concentran mayor atención que las prácticas y capacitaciones sobre derechos humanos. Sobre estos ejes de seguridad, de acuerdo con la información oficial relevada, entre 2014 y $2019^{23}$ Paraguay estableció lazos con once países ${ }^{24}$ y, además, recibió apoyo de la OIM, la Organización de Estados Americanos (OEA) y la Interpol. En este sentido, a partir de la securitización de su política migratoria, Paraguay ha fortalecido ciertas relaciones bilaterales y multilaterales con países y organizaciones interesadas en proveer servicios, capacitaciones, y equipos para tal fin.

En diciembre de 2014, la DGM y el Servicio de Inmigración de la República de Corea firmaron un Memorándum de Entendimiento para cooperar en materia migratoria en lo relativo a tecnología, seguridad, procedimientos y capacitación del personal. El objetivo de este documento fue evaluar el funcionamiento actual del control migratorio paraguayo para poder identificar las "necesidades urgentes en el aspecto tecnológico" sobre las cuales brindar asistencia, considerando a Corea como un actor clave en el proceso de "modernización" encarado por Paraguay (DGM, 2014, 15 de diciembre). En el ámbito de la capacitación migratoria, ese memorándum y otros instrumentos bilaterales ${ }^{25}$, posibilitaron que, en 2015 , un grupo de funcionarios

\footnotetext{
22 En adelante cuando se hace referencia al término de (in)seguridad se remite esa idea de Bigo (2006).

23 Se consideró hasta el mes de septiembre inclusive.

24 Argentina, Australia, Brasil, Canadá, Chile, China-Taiwán, Colombia, Corea del Sur, Estados Unidos, Perú y Reino Unido.

25 Por ejemplo, el acuerdo de cooperación bilateral entre Paraguay y la Agencia de Cooperación Internacional de Corea (KOICA) suscrito en 2013 (DGM, 1 de diciembre de 2015).
} 
viajara a Seúl para asistir a un curso de especialización en “Gestión e Inspección de la Inmigración", visitando incluso varios puestos de control migratorio en ciudades coreanas como parte de las actividades (DGM, 2015, 3 de marzo). La formación impartida a funcionarios paraguayos también implicó circulación de saberes como “(...) nuevas técnicas y habilidades de gerenciamiento migratorio; políticas de inmigración; sistemas de control fronterizo, de refugio y de nacionalidad; mecanismos de verificación de visas e inspección de pasaportes; migración y cooperación internacional, entre otros" (DGM, 2015, 1 de diciembre, párr. 7).

Otro país con el que Paraguay acordó colaboraciones en materia migratoria fue Colombia. Las cancillerías de ambos Estados rubricaron un Memorándum de Entendimiento en 2014, que abarcaba el tratamiento de cuestiones como la prevención, asistencia e investigación sobre la trata de personas, si bien se reconocía que “(...) casi no se han dado casos denunciados de víctimas extranjeras que arriban a Paraguay como país de tránsito o de destino (...)” (DGM, 2015, 19 de marzo, párr. 5). En 2017, Paraguay y Argentina firmaron un acuerdo de cooperación para la prevención, investigación y detección de casos de trata de personas, buscando fortalecer el trabajo en conjunto. Este acuerdo bilateral contempló puntos más amplios “(...) relacionados a la seguridad migratoria, como el intercambio de información, coordinación y fortalecimiento de programas fronterizos para prevenir, reprimir y sancionar (...) la trata de personas y delitos conexos" (DGM, 2017, 17 de marzo, párr. 2). Sobre la misma temática, una delegación paraguaya asistió a un taller impartido ese año por la OIM e instituciones del Mercosur (DGM, 2017, 31 de octubre). En 2019, otro país que ha dispuesto capacitación sobre trata y tráfico de personas a funcionarios estatales paraguayos ha sido Chile (DGM, 2019, 31 de julio).

Referido a la seguridad en temas migratorios, Estados Unidos ha impartido un taller para servidores públicos del área jurídica y de seguridad migratoria de la DGM, relativo al tráfico de personas, lavado de dinero y técnicas de entrevista para extranjeros que quieran radicarse en Paraguay, englobando estas actividades en la lucha contra crímenes transnacionales (DGM, 2018, 14 de junio). La DGM también recibió en 2016 y 2017 visitas oficiales de autoridades diplomáticas y de la Agencia de Servicios Fronterizos de Canadá (CBSA, por su sigla en inglés), que se mostraron con intenciones de establecer canales de cooperación bilaterales para colaborar en la gestión migratoria y las estrategias de control fronterizo del país sudamericano, que a su vez “(...) redunden en beneficio de la seguridad regional” (DGM, 2016, 15 de febrero; DGM, 2017, 14 de septiembre). Recientemente, Australia se ha mostrado interesada en la posibilidad de establecer un acuerdo de cooperación con Paraguay sobre seguridad e intercambio de información migratoria (DGM, 2019, 3 de mayo).

Siguiendo la misma senda, la capacitación sobre técnicas de detección de documentos falsos o fraudulentos al personal migratorio paraguayo ha sido un foco constante por parte de la OIM (DGM, 2014, 5 de agosto). Igualmente, el Rei- 
no Unido ha desplegado cursos dirigidos a los funcionarios migratorios sobre el tema, con el fin de "(...) proporcionar conciencia sobre el abuso de éstos y la criminalidad asociada, además de discutir las tendencias regionales de falsificación" (DGM, 2017, 6 de marzo, párr. 3). Estados Unidos, como parte de su instrucción sobre procedimientos y técnicas para el control migratorio, ha impartido cursos en 2015 para reconocer documentos fraudulentos en el marco del Programa de Asistencia Antiterrorista (ATA) (DGM, 2015, 30 de junio) y ha reconsiderado el mismo tópico, así como la especialización en técnicas de entrevistas dirigidas a migrantes dentro de sus planes de capacitación para funcionarios paraguayos de 2018 (DGM, 2018, 8 de febrero). Asimismo, Canadá ha brindado capacitación a inspectores de la DGM sobre "identificación de impostores" (DGM, 2018, 30 de noviembre, párr. 2). Como contribución a la gestión migratoria, en 2014 y 2017, la República de China-Taiwán donó equipos ${ }^{26}$ a la DGM para montar un laboratorio de análisis de documentos de identidad (DGM, 2014, 31 de octubre). Esto se suma a la adquisición en 2017 por parte de la DGM del Software Forensic Studio para la detección de documentación falsa o adulterada (DGM, 2017, 14 de marzo) y a la donación en 2016 de dispositivos informáticos ${ }^{27}$ para cursos internos de entrenamiento realizada por Estados Unidos (DGM, 2016, 22 de enero).

Los "servicios" profesionales para gestionar la (in)seguridad en Paraguay tienen como protagonista principal a la OIM, aliada en la "modernización migratoria" del país, que se ha transformado en la proveedora de adiestramiento, sistemas y equipamientos para el control migratorio y de fronteras. Durante la nueva etapa de la "Política Nacional de Migraciones", la alianza para la cooperación securitaria sobre migraciones más importante ha sido entre Paraguay y la OIM. El organismo ha sido fundamental en los cambios realizados por el país sudamericano. La imbricación entre ambos actores es tan contundente que en 2014 se creó una hoja de ruta por cuatro años denominada "Plan Estratégico Nacional (PEN) de la OIM en el Paraguay". En ese documento, se advertía que el control fronterizo era poco seguro y se recomendaba mejorar la gestión migratoria a través de capacitación a funcionarios e incorporación de tecnologías de control migratorio (OIM, 2014). Siguiendo esos pasos, Paraguay adoptó en 2015 el Sistema Interconectado de Registro e Identificación de Personas y el Sistema de Información y Análisis de Datos sobre la Migración (PIRS/MIDAS, por su sigla en inglés). El sistema MIDAS diseñado por la OIM es un programa biométrico ${ }^{28}$ de control migratorio y fronterizo $^{29}$ que en América Latina funciona solo en Paraguay y Belice, siendo utilizado

\footnotetext{
26 Compuesto por lámparas ultravioletas para detección de documentos falsos, computadoras, impresoras, pizarra acrílica, lupas y otros materiales de inspección y detección (DGM, 31 de octubre de 2014).

27 Se trató de una computadora, proyectores y tabletas digitales (DGM, 22 de enero de 2016).

28 Recaba impresiones de huellas dactilares y reconocimiento facial.

29 Está interconectado con las bases de datos de Interpol.
} 
también en países asiáticos ${ }^{30} \mathrm{y}$, sobre todo, africanos ${ }^{31}$. El sistema MIDAS comenzó a implementarse en 2016 en fronteras estratégicas paraguayas con Argentina, Brasil y Bolivia, aunque actualmente está en fase de expansión.

La adquisición de estos sistemas provistos la OIM y, sobre todo, de estas perspectivas de "modernización" de la política migratoria asentadas fuertemente en la seguridad, colocó en pocos años a un país de emigración, como Paraguay, a la vanguardia de un proceso de securitización de las migraciones. Este afán por la visión securitaria ha llegado a plasmarse incluso en los considerandos del proyecto de la nueva ley de migraciones de 2016, donde se menciona la "(...) modernización de los puestos de control fronterizos por medios digitales biométricos". Con estos métodos se intentan proyectar construcciones políticas concretas, que asocian la inmigración con la "amenaza", lo que habilita y legitima una lógica de mayor seguridad. La biometría está construida sobre esa (in)securitización, en la que los posibles riesgos de seguridad son creados, alimentados y reproducidos por el propio sistema de Estados y organismos internacionales como la OIM, OACI e Interpol, entre otros ${ }^{32}$. En esta dirección, se puede encuadrar a la OIM como un actor propagador de esta lógica de (in)seguridad en Paraguay y considerarlo, según definen Ashutosh \& Mountz (2011), como un actor fundamental dentro del proceso de securitización global de las migraciones.

Dentro de este marco, la frontera que se difumina es la que tiene que ver con las labores propias del Estado, en este caso paraguayo, y la "asistencia técnica" de un organismo internacional, como la OIM. Una muestra de ello, que excede un esquema clásico de cooperación, fue la delegación a la OIM del proceso de selección y contratación, bajo la figura de "consultor", de inspectores migratorios para trabajar en el principal aeropuerto del país en $2018^{33}$. La delegación a la OIM de esta atribución de competencias propia del Estado, puede ser una muestra de cómo operan las dinámicas del "control cooperativo" o externalización mencionado por Alvites Baiadera (2019) en Sudamérica. No se trata de un caso aislado. De hecho, a nivel global, la OIM actúa en las estrategias de control fronterizo ${ }^{34}$, operando en nombre de los Estados soberanos, pero más allá de sus límites tradicionales (Ashutosh \& Mountz, 2011). Otro ejemplo que se escuda en este apoyo a la gestión migratoria securitaria, es el desempeño de la propia OIM (en acuerdo con la empresa VFS

30 Camboya e Islas Marshall.

31 Burkina Faso, Chad, Congo, Guinea, Liberia, Madagascar, Malawi, Malí, Níger, Nigeria, República Democrática del Congo, Somalia, Sudán del Sur, Tanzanía, Uganda,y Yibuti.

32 Sobre el papel de estos organismos en la adopción de la biometría dentro del control migratorio, véase Santi Pereyra (2018).

33 Véase OIM (s.f.).

34 Los mismos autores indican que la OIM también ha colaborado con los Estados en tareas de transporte y prácticas de detención, promoviendo la contención de la migración, en lugar de su facilitación (Ashutosh \& Mountz, 2011). 
Global $^{35}$ ) como operadora del Canada Visa Aplication Centre (CVAC) en Paraguay, que se encarga de procesar los datos migratorios y biométricos de las solicitudes de visas para Canadá. Así, la OIM se configura en Paraguay como un organismo activo en el control migratorio y fronterizo, al que ciertos Estados externalizan sus funciones tradicionales, que exporta y transnacionaliza sus "saberes" de control migratorio, incluso a países de emigración (como Paraguay), abarcando en este camino a actores públicos y privados.

\section{Conclusiones}

Paraguay ha reconfigurado recientemente su política migratoria siguiendo las tendencias de otros Estados sudamericanos. La inclusión de una perspectiva de derechos humanos ha fundamentado los cambios iniciados en este siglo, que se han remarcado desde 2014. Aunque continúa siendo un país de emigración, este camino hacia la "modernización" de su política migratoria ha llevado a Paraguay a implementar medidas políticas en las que conviven los derechos humanos con la securitización de las migraciones como enfoques para tratar el fenómeno.

Como se ha relevado, en la práctica, la categoría de seguridad ha obtenido mayor atención que la perspectiva de los derechos humanos. La seguridad representa una continuidad entre la vieja y la nueva política migratoria planteada: la seguridad nacional de la Ley de 1996, aún en funciones, actualmente comparte espacios políticos con un enfoque sofisticado y tecnológico del control migratorio y fronterizo. Esto ha impulsado un proceso de securitización migratoria en el Estado paraguayo.

El nexo entre migración, seguridad y derechos humanos existente en Argentina (Pereira, 2019), en el contexto paraguayo se compatibiliza con la idea de "migración ordenada", que se apoya en criterios de control y selectividad. Esta selectividad en torno a la inmigración apela a elementos de seguridad y de utilidad para el Estado paraguayo. A la par, los derechos humanos se subordinan a la "migración ordenada" delimitada por Paraguay, legitimando el proceso de securitización en el que están inmersas las políticas migratorias de ese país. Una muestra de ello, es la propuesta de establecer convenios migratorios para hacer efectivo el control perseguido y la selectividad deseada. Justamente, teniendo la seguridad como meta, la "migración ordenada" propuesta por OIM tiene como objetivo restringir la inmigración considerada inconveniente, entendiendo que para ello es necesario vigilar todo el trayecto migratorio de los flujos (Santi, 2019) y los convenios facilitan eso.

35 Esta empresa presta servicios a varios gobiernos del mundo. Para ver su actividad comparativamente en el caso de otro país sudamericano, Ecuador, consultar Gil Araujo, Santi y Jaramillo (2017). 
Paraguay ha apelado al discurso de derechos humanos al mismo tiempo que ha reforzado sus lógicas de control migratorio, utilizando la vía de la cooperación con otros Estados para cercar esa vigilancia, integrándose dentro de las dinámicas de "control cooperativo" o externalización que Alvites Baiadera (2019) menciona como parte del régimen de frontera sudamericano. La nueva "Política Nacional de Migraciones" le ha permitido a Paraguay ser percibido con mayor interés por parte de otros países y organismos internacionales, presentándose como un mercado potencial para la implantación de enfoques políticos y nuevos saberes técnicos para encarar el fenómeno migratorio. Paraguay se ha convertido en un campo de acción y atracción para los "servicios" de seguridad brindados por diversos actores internacionales, conllevando a la aparición de una cooperación securitaria sobre migraciones. Esta implica el establecimiento de lazos de colaboración con países y organismos internacionales con fines de control migratorio y fronterizo para la formación (capacitación en contenidos políticos y tecnológicos), provisión de servicios, adquisición de sistemas tecnológicos y equipamientos; lo que impacta directamente en las prácticas a través del cambio de concepciones y procedimientos.

La cooperación en seguridad concentra mayor atención que las prácticas y capacitaciones sobre derechos humanos. Existe un pronunciado interés de cooperación securitaria sobre migraciones entre Paraguay y varios países y organismos internacionales en lo que se refiere a asuntos de seguridad, control migratorio y vigilancia fronteriza, para fortalecer (aún más, si cabe) su nexo migración-seguridad. Por este motivo, entre 2014 y 2019, Paraguay ha establecido reuniones bilaterales con Argentina, Australia, Brasil, Canadá, Chile, China-Taiwán, Colombia, Corea del Sur, Estados Unidos, Perú y Reino Unido. Además de contactos con la OEA y la Interpol por los mismos temas, siendo la cooperación con OIM la más importante de acuerdo a lo detallado en este artículo, que ha llegado incluso a superar el rol tradicional de un colaborador.

No se puede analizar la política migratoria paraguaya sin contemplar a la OIM como un actor central del proceso de securitización de las migraciones y como un colaborador esencial en la cooperación securitaria sobre migraciones. La OIM ha acompañado el camino emprendido por Paraguay en los "Lineamientos para la elaboración de una Política Nacional de Migraciones", de 2003; el "Programa integral para el fortalecimiento de las capacidades institucionales del gobierno de Paraguay en materia migratoria y lucha contra la trata de personas" de 2008; y la actual "Política Nacional de Migraciones" de 2015.

Históricamente, el asesoramiento y la capacitación han sido mecanismos reproductivos centrales a nivel global que ha utilizado la OIM para promover la idea de la "migración ordenada", alentando la implantación de políticas y prácticas de control migratorio. En las acciones desplegadas por la OIM en colaboración con el gobierno paraguayo, se puede apreciar su injerencia (en menor grado) en cuestiones de derechos humanos, así como su importante impronta en asuntos de 
seguridad. Los "servicios" profesionales brindados por la OIM para gestionar la (in)seguridad en Paraguay la han transformado en proveedora de adiestramiento, sistemas y equipamientos para el control migratorio y de fronteras. La adopción del sistema biométrico de control migratorio y fronterizo MIDAS, diseñado por OIM, convierte a un país de emigración como Paraguay en el único Estado de referencia que ha aplicado este tipo de tecnología de vigilancia en Sudamérica. Paraguay no es un caso aislado, dado que la OIM aplica con frecuencia el mismo abordaje en otros países del hemisferio sur, como se ha comprobado en Santi (2019). La OIM se configura en Paraguay como un organismo activo en el control migratorio y fronterizo, que exporta y transnacionaliza sus "saberes" de control migratorio hacia ese país. En este sentido, Paraguay se ha transformado en un receptor (y no emisor) de "servicios" de seguridad aplicados a la migración, tornándose dependiente de otros actores internacionales, como la OIM, que actúan como "proveedores" interesados en rentabilizar el control migratorio y fronterizo paraguayo.

\section{Referencias bibliográficas}

Alvites Baiadera, A. (2019). Migraciones internacionales, fronteras y Estados. ¿Cómo interpretar el régimen de frontera desde América del Sur? Desafíos, 31(1), 123-156.

Ashutosh, I. \& Mountz, A. (2011). Migration management for the benefit of whom? Interrogating the work of the International Organization for Migration. Citizenship Studies, 15(1), 21-38. DOI: 10.1080/13621025.2011.534914

Bigo, D. (2002). Security and immigration: Toward a critique of the governmentality of unease. Alternatives, (27), 63-92. DOI: https://doi. org/10.1177/03043754020270S105

Bigo, D. (2006). Globalized (in)security: the field and the ban-opticon. En D. Bigo \& A. Tsoukala (eds.), Illiberal Practices in Liberal Regimes: The (In) Security Games (pp. 5-49). París: L'Harmattan.

Clavijo Padilla, J. (2014). La política migratoria colombiana en el período 2002-2010: el programa Colombia Nos Une (CNU). Córdoba: Editorial del Centro de Estudios Avanzados/Universidad Nacional de Córdoba.

Concha Villanueva, S. (2018). Propuestas para regular las migraciones en Chile y la obstinación del securitismo. URVIO-Revista Latinoamericana de Estudios de Seguridad, (23), 110-126. DOI: http://dx.doi.org/10.17141/urvio.23.2018.3571

Courtis, C. y Pacecca, M. I. (2007). Migración y derechos humanos: una aproximación crítica al "nuevo paradigma" para el tratamiento de la cuestión migratoria en la Argentina. Revista Jurídica de Buenos Aires, 183-200.

Dirección General de Migraciones (DGM). (s.f.). Misión y visión. Recuperado de http:// www.migraciones.gov.py/index.php/institucion/mision-y-vision 
Dirección General de Migraciones (DGM). (1 de abril de 2014). La Dirección General de Migraciones dió apertura a nuevo ciclo de Capacitaciones con expertos internacionales de la OIM. Dirección General de Migraciones. Recuperado de http://www. migraciones.gov.py/index.php/noticias/la-direccion-general-de-migraciones-dioapertura-nuevo-ciclo-de-capacitaciones-con-expertos-internacionales-de-la-oim

Dirección General de Migraciones (DGM). (16 de julio de 2014). La DGM apuesta a la capacitación de su personal en todas las áreas. Dirección General de Migraciones. Recuperado de http://www.migraciones.gov.py/index.php/noticias/la-dgmapuesta-la-capacitacion-de-su-personal-en-todas-las-areas

Dirección General de Migraciones (DGM). (5 de agosto de 2014). Migraciones y la OIM oficializan los proyectos de cooperación interinstitucional ante el Presidente de la República. Dirección General de Migraciones. http://www.migraciones. gov.py/index.php/noticias/migraciones-y-la-oim-oficializan-los-proyectos-decooperacion-interinstitucional-ante-el-presidente-de-la-republica

Dirección General de Migraciones (DGM). (31 de octubre de 2014). Embajador de Taiwán hizo entrega de equipos donados a la DGM. Dirección General de Migraciones. Recuperado de http://www.migraciones.gov.py/index.php/noticias/ embajador-de-taiwan-hizo-entrega-de-equipos-donados-la-dgm

Dirección General de Migraciones (DGM). (15 de diciembre de 2014). Migraciones de Paraguay y Corea suscribieron acuerdo de cooperación. Dirección General de Migraciones. Recuperado de www.migraciones.gov.py/index.php/noticias/ migraciones-de-paraguay-y-corea-suscribieron-acuerdo-de-cooperacion

Dirección General de Migraciones (DGM). (3 de marzo de 2015). Funcionarios se capacitan en Corea sobre gestión de la inmigración. Dirección General de Migraciones. Recuperado de http://www.migraciones.gov.py/index.php/noticias/ funcionarios-se-capacitan-en-corea-sobre-gestion-de-la-inmigracion

Dirección General de Migraciones (DGM) . (19 de marzo de 2015). Paraguay y Colombia coordinan mecanismos de cooperación contra la trata de personas. Dirección General de Migraciones. Recuperado de www.migraciones.gov.py/index.php/ noticias/paraguay-y-colombia-coordinan-mecanismos-de-cooperacion-contrala-trata-de-personas

Dirección General de Migraciones (DGM). (14 de mayo de 2015). La DGM participó en el V Congreso Iberoamericano de Autoridades Migratorias Dirección General de Migraciones. Recuperado de http://www.migraciones.gov.py/index.php/noticias/ la-dgm-participo-en-el-v-congreso-iberoamericano-de-autoridades-migratorias

Dirección General de Migraciones (DGM). (30 de junio de 2015). Embajadora de EE.UU. reafirma lazos de cooperación con Migraciones Paraguay. Dirección General de Migraciones. Recuperado de www.migraciones.gov.py/index.php/noticias/ embajadora-de-eeuu-reafirma-lazos-de-cooperacion-con-migraciones-paraguay

Dirección General de Migraciones (DGM). (1 de diciembre de 2015). Delegación migratoria de Corea realiza visita oficial a Paraguay. Dirección General de Migraciones. 
Recuperado de http://www.migraciones.gov.py/index.php/noticias/delegacionmigratoria-de-corea-realiza-visita-oficial-paraguay

Dirección General de Migraciones (DGM). (22 de enero de 2016). Embajada de Estados Unidos realiza donación de equipos para capacitación de funcionarios. Dirección General de Migraciones. Recuperado de http://www.migraciones.gov.py/index. $\mathrm{php} /$ noticias/embajada-de-estados-unidos-realiza-donacion-de-equipos-paracapacitacion-de-funcionarios

Dirección General de Migraciones (DGM). (15 de febrero de 2016). Representante del Servicio Fronterizo de Canadá realiza visita oficial a la DGM. Dirección General de Migraciones. Recuperado de www.migraciones.gov.py/index.php/noticias/ representante-del-servicio-fronterizo-de-canada-realiza-visita-oficial-la-dgm

Dirección General de Migraciones (DGM). (24 de junio de 2016). Comisión de Fronteras inicia coordinación dentro del Plan Nacional de Derecho a la Identidad. Dirección General de Migraciones. Recuperado de http://www.migraciones.gov. py/index.php/noticias/comision-de-fronteras-inicia-coordinacion-dentro-delplan-nacional-de-derecho-la-identidad

Dirección General de Migraciones (DGM). (14 de julio de 2016). Debaten sobre niñez migrante y derechos humanos en importante taller regional. Dirección General de Migraciones. Recuperado de http://www.migraciones.gov.py/index.php/noticias/ debaten-sobre-ninez-migrante-y-derechos-humanos-en-importante-taller-regional

Dirección General de Migraciones (DGM). (6 de marzo de 2017). Funcionarios migratorios se capacitan en taller ofrecido por la Embajada Británica. Dirección General de Migraciones. Recuperado de www.migraciones.gov.py/index.php/noticias/funcionariosmigratorios-se-capacitan-en-taller-ofrecido-por-la-embajada-britanica

Dirección General de Migraciones (DGM). (14 de marzo de 2017). Migraciones introduce nueva tecnología para la detección de documentos de viaje fraudulentos. Recuperado www.migraciones.gov.py/index.php/noticias/migraciones-introduce-nueva-tecnologia-para-la-deteccion-de-documentos-de-viaje-fraudulentos

Dirección General de Migraciones (DGM). (17 de marzo de 2017). Organismos de seguridad de Argentina y Paraguay firmaron acuerdo bilateral de cooperación y combate a la trata de personas. Dirección General de Migraciones. Recuperado de www.migraciones.gov.py/index.php/noticias/organismos-de-seguridad-deargentina-y-paraguay-firmaron-acuerdo-bilateral-de-cooperacion-y-combatela-trata-de-personas

Dirección General de Migraciones (DGM). (14 de septiembre de 2017). Autoridades de Paraguay y Canadá reafirman cooperación en materia migratoria. Dirección General de Migraciones. Recuperado de http://www.migraciones.gov.py/index. $\mathrm{php} /$ noticias/autoridades-de-paraguay-y-canada-reafirman-cooperacion-enmateria-migratoria

Dirección General de Migraciones (DGM). (9 de octubre de 2017). Gobierno de Taiwán realiza donación de equipos para entrenamiento de inspectores migratorios. 
Dirección General de Migraciones. Recuperado de www.migraciones.gov.py/ index.php/noticias/gobierno-de-taiwan-realiza-donacion-de-equipos-paraentrenamiento-de-inspectores-migratorios

Dirección General de Migraciones (DGM). (31 de octubre de 2017). Representantes de la DGM se capacitan para la identificación y derivación de personas en situación de trata. Dirección General de Migraciones. Recuperado de www.migraciones. gov.py/index.php/noticias/representantes-de-la-dgm-se-capacitan-para-laidentificacion-y-derivacion-de-personas-en-situacion-de-trata

Dirección General de Migraciones (DGM). (8 de febrero de 2018). Migraciones traza planes de cooperación con la Embajada de Estados Unidos para el 2018. Dirección General de Migraciones. Recuperado de www.migraciones.gov.py/index.php/noticias/migraciones-traza-planes-de-cooperacion-con-la-embajada-de-estados-unidos-para-el-2018

Dirección General de Migraciones (DGM). (14 de junio de 2018). Embajada de EE.UU. brindó taller de capacitación a funcionarios del área jurídica y de seguridad migratoria. Dirección General de Migraciones. Recuperado de www.migraciones. gov.py/index.php/noticias/embajada-de-eeuu-brindo-taller-de-capacitacionfuncionarios-del-area-juridica-y-de-seguridad-migratoria

Dirección General de Migraciones (DGM). (30 de noviembre de 2018). Inspectores migratorios del Aeropuerto Silvio Pettirossi se capacitan en detección de documentos de viaje fraudulentos. Dirección General de Migraciones. Recuperado de http://www. migraciones.gov.py/index.php/noticias/inspectores-migratorios-del-aeropuertosilvio-pettirossi-se-capacitan-en-deteccion-de-documentos-de-viaje-fraudulentos

Dirección General de Migraciones (DGM). (3 de mayo de 2019). Titular de Migraciones recibió a representantes migratorios y de seguridad del Gobierno de Australia. Dirección General de Migraciones. Recuperado de http://www.migraciones.gov. py/index.php/noticias/titular-de-migraciones-recibio-representantes-migratorios-y-de-seguridad-del-gobierno-de-australia

Dirección General de Migraciones (DGM). (31 de julio de 2019). Funcionarios migratorios son capacitados en curso sobre metodología de investigación de trata de personas. Dirección General de Migraciones. Recuperado de http://www.migraciones.gov.py/index.php/noticias/funcionarios-migratorios-son-capacitados-encurso-sobre-metodologia-de-investigacion-de-trata-de-personas

Domenech, E. (2009). La visión estatal sobre las Migraciones en la Argentina reciente. de la retórica de la exclusión a la retórica de la inclusión. En E. Domenech (comp.), Migración y política: el Estado interrogado. Procesos actuales en Argentina y Sudamérica (pp. 21-69). Córdoba: Universidad Nacional de Córdoba.

Domenech, E. (2011a). Crónica de una "amenaza” anunciada. Inmigración e 'ilegalidad': visiones de Estado en la Argentina contemporánea. En B. Feldman-Bianco, L. Rivera Sánchez, C. Stefoni y M.I. Villa Martínez (comps.) La Construcción del sujeto migrante en América Latina: Prácticas, representaciones y categorías (pp. 31-77). Quito: FLACSO/CLACSO/Universidad Alberto Hurtado. 
Domenech, E. (2011b, mayo). La gobernabilidad migratoria en la Argentina: hacia la instauración de políticas de control con "rostro humano". Ponencia presentada en el IV Congreso de la Red Internacional de Migración y Desarrollo, Quito, FLACSO-Ecuador.

Domenech, E. (2013). "Las migraciones son como el agua": Hacia la instauración de políticas de "control con rostro humano". La gobernabilidad migratoria en la Argentina. Polis. Revista Latinoamericana, (35), 1-16. DOI: http://dx.doi. org/10.4067/S0718-65682013000200006

Domenech, E. (2017). Las políticas de migración en Sudamérica: elementos para el análisis crítico del control migratorio y fronterizo. Terceiro Milênio: Revista Crítica de Sociologia e Política, 8(1), 19-48. Recuperado de https://ri.conicet.gov. ar/handle/11336/58156

Marques, D., Rodrigues, R., Rezende, D., Soares, W. y Vélez, J. (2013). La circularidad de los "brasiguayos" en las fronteras de Paraguay y Brasil. Estudios Sociológicos, 31(93), 865-898. Recuperado de https://estudiossociologicos.colmex.mx/index. php/es/article/view/110

García, L. (2016). Migraciones, Estado y una política del derecho humano a migrar: ¿Hacia una nueva era en América Latina?. Colombia Internacional, (88), 107-133. DOI: https://doi.org/10.7440/colombiaint88.2016.05

Gil Araujo, S., Santi, S. y Jaramillo, V. (2017). Externalización del control migratorio y políticas de migración familiar en Europa: instrumentos para un gobierno deslocalizado de la migración. En R,J. (coord.) Migración, Estado, y políticas. Cambios y continuidad en América del Sur (pp. 197-213). La Paz: CELAG.

López, M. (2010). La democracia en Paraguay. Un breve repaso sobre los partidos políticos tradicionales, el sistema electoral y el triunfo de Fernando Lugo Méndez. Revista Enfoques: Ciencia Política y Administración Pública, 8(13), 89-106.

López, M. (2012). ¿Emigrados, inmigrantes, repatriados o retornados? Un análisis de las leyes vigentes en materia migratoria (n. $978 / 96$ y n.ㅇ 3958) en Paraguay. Revista Temas de Antropología y Migración, (4), 98-118.

Magliano, M. J. y Clavijo, J. (2011). La trata de personas en la agenda política sudamericana sobre migraciones: la securitización del debate migratorio. Revista Análisis Político, (71), 149-163. Recuperado de https://revistas.unal.edu.co/index.php/ anpol/article/view/44244

MRE, OIM y UNFPA. (2003). Lineamientos para una Política Nacional de Migraciones. Asunción: MRE/OIM/UNFPA.

Novick, S. (2012). Migraciones en el Cono Sur: políticas, actores y procesos de integración. los casos de Uruguay, Paraguay y Chile. Perspectivas, 42, 79-114.

Oddone, H. (2011). Impactos de la migración en el desarrollo nacional: Una aproximación histórico-social. En G. Halpern (comp.), Perspectivas (críticas) en torno a los procesos migratorios del Paraguay (pp. 60-82). Asunción: Ápe Paraguay. 
Organización Internacional para las Migraciones (OIM). (s.f.). Nombre de la Convocatoria: Servicios de inspector migratorio en el Aeropuerto Internacional Silvio Pettirossi. Recuperado de https://paraguay.iom.int/?q=es/node/937

Organización Internacional para las Migraciones (OIM). (2011). Perfil Migratorio de Paraguay 2011. Buenos Aires: OIM.

Organización Internacional para las Migraciones (OIM). (2013). Régimen migratorio en la República del Paraguay. Relevamiento jurídico- institucional de la normativa migratoria en la República del Paraguay. Asunción: OIM.

Organización Internacional para las Migraciones (OIM). (2014). Plan Estratégico Nacional (PEN) de la Organización Internacional para las Migraciones (OIM) en el Paraguay 2014 - 2018. Asunción: OIM.

Organización Internacional para las Migraciones (OIM). (2017). Tendencias migratorias en América del Sur (Informe Migratorio Sudamericano n. ${ }^{\circ}$ ).

OIM/DGM/Ministerio del Interior. (2015). Política migratoria. República del Paraguay. Asunción: OIM/DGM/Ministerio del Interior.

Palau, T. (2011). El marco expulsivo de la migración paraguaya. Migración interna y migración externa. En G. Halpern (Comp.), Perspectivas (críticas) en torno a los procesos migratorios del Paraguay (pp. 40-59). Asunción: Ápe Paraguay.

Presidente de la República de Paraguay. (2015) Anexo del Decreto n.o 4.483 de 2015 (27 de noviembre), por el cual se aprueba la Política Nacional de Migraciones de la República del Paraguay, Asunción.

Congreso Nacional de Paraguay (Honorable Cámara de Diputados. (17 de agosto de 2016) Proyecto de Ley de migraciones, Asunción.

Presidente de la República de Paraguay. (28 de agosto de 1997) Decreto n.ำ 18.295, reglamenta la Ley n. 978/96 de migraciones, Asunción.

Presidente de la República de Paraguay Ministerio de Relaciones Exteriores . (12 de diciembre de 2000) Decreto n. $\stackrel{0}{11.484}$, por el cual se constituye el grupo de trabajo interinstitucional encargado de consolidar la posición paraguaya que será planteada en el seno del grupo binacional para el estudio de temas de desarrollo de integración transfronteriza, resultante de la reunión de trabajo bilateral Paraguay-Brasil, celebrada en el marco del seminario sobre migración, realizado en la ciudad de Sao Paulo, Brasil., Asunción.

Presidencia de la República de Paraguay, Ministerio de Relaciones Exteriores (3 de septiembre de 2002) Decreto n.. 18.467, por el cual se amplía y modifica el Decreto n. ${ }^{\circ} 11.484$, del 12 de diciembre de 2000, que constituye el grupo de trabajo interinstitucional encargado de consolidar la posición paraguaya en el grupo binacional para el estudio de temas de desarrollo de integración transfronteriza entre Paraguay y Brasil.

Presidencia de la República de Argentina. (20 de febrero de2007) Decreto n.o 9.032, por el cual se establecen requisitos migratorios diferenciados para Argentinos 
Nativos en reciprocidad al Programa Nacional de Normalización Documentaria desarrollado por la República Argentina, Asunción.

Presidencia de la República de Paraguay. (27 de noviembre de 2015) Decreto n. 0 4.483, por el cual se aprueba la Política Nacional de Migraciones de la República del Paraguay, Asunción.

Presidente de la República de Paraguay. (8 de noviembre de 1996) Ley n.o 978 de Migraciones.

Congreso de la República de Paraguay. (9 de abril de 2008) Ley n.o 3452, que aprueba la Convención internacional sobre la protección de los derechos de todos los trabajadores migratorios y de sus familiares, Asunción.

Congreso de la República de Paraguay. (4 de octubre de 2011), Ley n.ํㅜ 4.429 que regulariza la residencia de extranjeros en situación migratoria irregular, Asunción.

Pereira, A. (2019). El nexo entre migración, seguridad y derechos humanos en la política migratoria de Argentina (1990-2015) . Desafíos, 31(1), 273-309. DOI: http:// dx.doi.org/10.12804/revistas.urosario.edu.co/desafios/a.6031

PNUD/UNFPA/UNICEF/UNIFEM/OIM. (2009). Ampliando horizontes: emigración internacional paraguaya. Asunción: PNUD/UNFPA/UNICEF/UNIFEM/OIM.

Ruiz Muriel, M. C. y Álvarez Velasco, S. (2019). Excluir para proteger: la "guerra" contra la trata y el tráfico de migrantes y las nuevas lógicas de control migratorio en Ecuador. Estudios Sociológicos, 37(111), 689-725. DOI: http://dx.doi.org/10.24201/ es.2019v37n111.1686

Santi Pereyra, S. (2017). Las implicancias de la UE en la política exterior de España (19962004): el tratamiento de las migraciones en las relaciones bilaterales con Ecuador. (Tesis de maestría), Universidad Nacional de Córdoba, Córdoba, Argentina.

Santi Pereyra, S. (2018). Biometría y vigilancia social en Sudamérica: Argentina como laboratorio regional de control migratorio. Revista mexicana de ciencias políticas y sociales, 63(232), 247-268. DOI: https://dx.doi.org/10.22201/ fcpys.2448492xe.2018.232.56580

Santi, S. \& Clavijo, J. (en prensa). La configuración de las políticas de migración circular en Sudamérica. Los acuerdos de regulación laboral de España con Colombia y Ecuador. Revista Desafíos.

Santi, S. (2019, junio). Desde y hacia la migración “ordenada”. Multilateralismo y capacity-building como motores de las políticas de control migratorio global. Ponencia presentada en The Migration Conference 2019, Bari, Universidad de Bari.

Congreso de la República de Paraguay. (2019). Proyecto de Ley: “De migraciones”, ficha técnica del expediente. Recuperado de http://silpy.congreso.gov.py/expediente/107529

Souchaud, S. (2008). De los campos agrícolas a los centros financieros. Caracteres de la inmigración internacional en Paraguay a principios del siglo XXI. Folia Histórica del Nordeste, (17), 43-62. 
Torpey, J. (2006). Yendo y viniendo. La monopolización estatal de los medios legítimos me movimiento. Zona Abierta, (116/117), 59-87.

Torpey, J. (2018). The Invention of the Passport: Surveillance, Citizenship and the State. Cambridge: Cambridge University Press. DOI:10.1017/9781108664271

Zubrzycki, B. (2018). Migración no autorizada y procesos de regularización en Argentina: el caso senegalés. Revista del CESLA. International Latin American Studies Review, (22), 367-382. Recuperado de https://www.revistadelcesla.com/index. php/revistadelcesla/article/view/514 